Retraction

\title{
Retraction: Yuan, N., et al. Laplacian Eigenmaps Feature Conversion and Particle Swarm Optimization-Based Deep Neural Network for Machine Condition Monitoring. Appl. Sci. 2018, 8, 2611, doi:10.3390/app8122611
}

\author{
Nanqi Yuan ${ }^{1,2, *}$, Wenli Yang ${ }^{1}{ }^{1}$, Byeong Kang ${ }^{1}$, Shuxiang $\mathrm{Xu}^{1}{ }^{1}$, Xiaolin Wang ${ }^{2}$ and Applied \\ Sciences Editorial Office ${ }^{3}$ \\ 1 Discipline of ICT, School of Technology, Environments and Design, University of Tasmania, Hobart TAS7005, \\ Australia; wenli.yang@utas.edu.au (W.Y.); byeong.kang@utas.edu.au (B.K.); shuxiang.xu@utas.edu.au (S.X.) \\ 2 School of Engineering, Australian Maritime College, University of Tasmania, Hobart TAS7005, Australia; \\ xiaolin.wang@utas.edu.au \\ 3 MDPI AG, St. Alban-Anlage 66, 4052 Basel, Switzerland; applsci@mdpi.com \\ * Correspondence: nanqi.yuan@utas.edu.au
}

The published article [1] has been retracted at the request of the authors. The co-authors were not aware that the article had been submitted for publication and do not agree to the publication of the paper in its current form. Thus, out of respect for the author's wishes and in agreement with the Applied Sciences Editorial Office, the paper will be marked as retracted. We apologize for any inconvenience caused by the removal of this article. We note that all authors are kept informed of submissions to Applied Sciences; however, in this case, incorrect email addresses were supplied to the Editorial Office.

Applied Sciences is a member of the Committee on Publication Ethics (COPE) and strives to uphold the highest ethical standards. The published article [1] is retracted and shall be marked accordingly.

\section{Reference}

1. Yuan, N.; Yang, W.; Kang, B.; Xu, S.; Wang, X. Laplacian Eigenmaps Feature Conversion and Particle Swarm Optimization-Based Deep Neural Network for Machine Condition Monitoring. Appl. Sci. 2018, 8, 2611. [CrossRef]

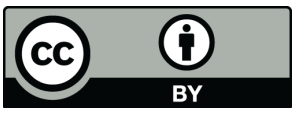

(C) 2020 by the authors. Licensee MDPI, Basel, Switzerland. This article is an open access article distributed under the terms and conditions of the Creative Commons Attribution (CC BY) license (http://creativecommons.org/licenses/by/4.0/). 